\title{
Bioavailability and Pharmacokinetics of Natural Volatile Terpenes in Animals and Humans
}

\author{
C. Kohlert' ${ }^{1}$ I. van Rensen², R. März³ , G. Schindler ${ }^{4}$, E. U. Graefe', M. Veit ${ }^{1}{ }^{*}$ \\ 1 Zentralinstitut Arzneimittelforschung $\mathrm{GmbH}$, Sinzig, Germany \\ 2 Department of Pharmaceutical Biology, Julius-von-Sachs-Institute for Biosciences, University of Würzburg, Würzburg, Germany \\ ${ }^{3}$ Bionorica Arzneimittel GmbH, Neumarkt/Opf., Germany \\ ${ }^{4}$ Department of Medicine I, Department of Complementary Medicine, Friedrich-Alexander-University Erlangen-Nürnberg, Erlangen, Germany
}

Received: December 24, 1999; Accepted: April 27, 2000

\begin{abstract}
Herbal medicinal products containing natural volatiles are used in the treatment of gastrointestinal diseases, pain, colds and bronchitis. Many pharmacological studies report a wide variety of in vitro effects, with anti-inflammatory and antimicrobial activities investigated most frequently. In comparison, relatively few studies on the bioavailability and pharmacokinetics have been carried out. Thus, the relevance of the in vitro activity to the therapeutic effects found in individual studies or documented in textbooks of phytotherapy is still not established. Further studies with essential oils and their single compounds providing supporting evidence of efficacy and demonstrating systemic availability are necessary. Such data could also be important in the context of safety.
\end{abstract}

Key words: Terpenes, volatiles, herbal medicinal products, bioavailability, pharmacokinetics.

\section{Introduction}

Essential oils are mixtures of lipophilic, liquid, volatile, and often terpenoid compounds present in higher plants. More than 3000 compounds have been described so far (1). The clinical efficacy of volatiles is particularly well-established for chronic pulmonary obstruction and acute bronchitis. For these indications clinical trials have been carried out with products containing 1,8-cineole (2), (3), (4), standardised myrtol (1,8-cineole, $\alpha$-pinene, limonene) (5) and thyme extract (6), (7). Further clinical studies have been carried out with peppermint oil for the treatment of irritable bowel syndrome (8), (9), non-ulcer dyspepsia (10), and tension-type headache (11). Numerous essential oils and their components have shown antimicrobial or antimycotic activity in in vitro studies (12), (13), (14), (15), (16).

Various other in vitro activities of volatile oils or compounds have been reported. However, the clinical relevance of these activities depends on the systemic availability of these compounds in the respective target organs. Thus, investigation of absorption, distribution and metabolism is necessary to link in vitro with in vivo data. They may also be important in con-

Planta Med 66 (2000) 495-505

(c) Georg Thieme Verlag Stuttgart · New York

ISSN: 0032-0943 text of the safety of herbal medicinal products containing natural volatiles. However, pharmacokinetics of volatile natural compounds have not yet been investigated satisfactorily. For several monoterpenoid and phenylpropanoid compounds there is a large amount of experimental data, but crucially especially with respect to humans - pharmacokinetic data are lacking.

This article reviews the data currently available on the systemic fate of natural volatile terpenes and phenylpropanes. Unfortunately, methodological details, particularly concerning validation of the analytical methods used have not been published for most of the studies. Therefore the results of those studies discussed here have to be considered cautiously, since the assays used might not match the requirements for analytical validation.

\section{Absorption and Systemic Availability \\ Dermal absorption}

Preparations of eucalyptus oil or mountain pine oil containing $\alpha$ - and $\beta$-pinene, camphor, 3-carene, and limonene have been used in most studies investigating the dermal absorption of essential oil compounds. These monoterpenoid compounds are readily absorbed after dermal application due to their lipophilic character. In order to avoid pulmonary absorption of evaporating compounds, an external air supply was provided for subjects in all studies. The skin did not represent a barrier to the diffusion of essential oil compounds (17), (18). Application by ointment to humans (19) and by bath to mice (18) resulted in a fast increase of plasma levels of the respective compounds. Maximum plasma levels were reached within 10 min of application (Fig. 1). It was shown that the extent of absorption depended on the size of treated skin area (18), skin properties, concentrations of the administered compounds and on time of exposure (17). However, the latter results were obtained in a study performed with only one subject and thus allow only limited conclusions (For details see Tables $\mathbf{1}$ and $\mathbf{2}$ ).

\section{Absorption after oral administration}

Only a few studies have addressed the absorption of volatile compounds after ingestion. From three studies with radio-labeled ${ }^{14} \mathrm{C}$-citral and $\left[1-{ }^{14} \mathrm{C}\right]$-trans-anethole administered to 
rats, the rate of absorption was estimated from the recovery of ${ }^{14} \mathrm{C}$ in faeces or urine, respectively $(20),(21),(22)$. The authors found $91-95 \%$ of the original activity in faeces and urine and determined seven metabolites by HPLC.

In a pharmacokinetic study with human volunteers, enteric coated capsules containing a defined mixture of limonene, 1,8 -cineole and $\alpha$-pinene, were investigated (41). As capsules were administered uncrushed and crushed (as a surrogate of a liquid application), some information on the absorption of 1,8 -cineole, which was the only compound detected in sufficient quantities in the plasma of all patients, can be extracted from this study. Patients who took the compounds as a capsule showed rather similar AUC values of 1,8-cineole to those who took the crushed capsules. The difference of the AUC of both administration modes was smaller than $7 \%$. As expected, the $C_{\max }$ of crushed capsules was more than $25 \%$ higher, and $t_{\max }$ was $0.75 \mathrm{~h}$ compared to $2.5 \mathrm{~h}$ with uncrushed capsules. These data suggest that the upper part of the gastrointestinal tract has no significant role with respect to the absorption of 1,8-cineole, but additional data would be helpful for a better understanding of absorption of ingested volatile compounds. Data derived from radio-labeled compounds as published in (20) are not sufficient, as long as no information on the identity of the carrier after metabolization is provided.

\section{Pulmonary absorption}

The volatile monoterpenes are particularly suitable for inhalation as used in the treatment of respiratory tract infections. Following inhalation, the compounds may be absorbed by the lung, and systemic availability is possible. In particular, for $\alpha-$ pinene, camphor and menthol this absorption route has been confirmed experimentally. The reported range was $54-76 \%$ of the dose supplied with inhaled air (Fig. 2) (23), (24), (25). However, estimation of the amount absorbed by calculating the difference between inhaled and exhaled air does not account for various uncertainties, (e.g., regarding mucosal drug deposition and metabolism) and does not consider distribution into other compartments. These concerns were supported by a study that measured blood levels, since only $4-6 \%$ of the amount assumed to be absorbed was actually found in the blood (24). Various factors seem to influence the extent of absorption during inhalation. Römmelt et al. (1988) demonstrated that pulmonary absorption depended on the kind of compound and the breathing mechanics of the subjects (23). Furthermore, it was evident that the release of compounds from water into the headspace depended on water temperature. At $80{ }^{\circ} \mathrm{C}, 12 \%$ camphor but only $5 \%$ menthol could be detected in the headspace within 15 minutes. (For details see Table 2.)

\section{Metabolism and Pharmacokinetics}

\section{Metabolism}

The metabolic fate of essential oil components depends on their individual chemical structure, and hence generalisation is not possible. Metabolites resulting from both phase-I and phase-II reactions have been reported.

Oxidation products of thymol and carvacrol were determined after oral administration of the genuine compounds to rats
(Fig. 3) (26). As phase-II metabolites, glucuronides or sulfates were detected in rats, rabbits, and humans (26), (27). Unchanged compounds could be detected only in small amounts in $24 \mathrm{~h}$ urine (27).

Several studies investigated the metabolic fate of $t$-anethole in humans and rodents (28), (29), (30). Determination of urinary metabolites suggested that in humans ${ }^{14} \mathrm{C}$-trans-anethole was completely metabolised by oxidative $O$-demethylation and various oxidative alterations of the side chain (30). Metabolites were excreted both unconjugated and conjugated to either glycine or glucuronic acid (29). No unchanged $t$ anethole was detected in urine. The pattern of metabolites in human urine differed only quantitatively from that seen in rodent urine. A dose-dependent variation in urinary metabolites was evident for $t$-anethole in rodents as well as ${ }^{14} \mathrm{C}$-eugenol in rats (31). For $t$-anethole the formation of phase-I metabolites was dose-dependent (28), whereas ${ }^{14} \mathrm{C}$-eugenol showed dose-dependent variations of conjugates.

Metabolites of menthol and peppermint oil were investigated in several human studies (32), (33), (34). After oral application of $\mathrm{L}-(-)$-menthol or peppermint oil, respectively, $35-50 \%$ of the original menthol content was excreted renally as menthol glucuronide. Only one study conducted by Bell et al. examined the free fraction of menthol and the glucuronide (34). No unchanged menthol and only traces of the sulphate conjugate were detected. There was a significant interindividual variation in the quantities excreted, which is likely to be due to differences in absorption and dietary habits (33). After administration of peppermint oil to ileostomy patients elimination of menthol glucuronide was less than after administration to healthy subjects. This indicated that absorption of menthol mainly took place in the small intestine (32).

Other components of peppermint oil like menthone or menthyl acetate were not assayed in these studies. However, these components could easily be metabolised to menthol and excreted as menthol glucuronide as well.

The metabolic fate of menthol was studied in detail in rats after oral administration (35), (36). Oxidation patterns were similar to thymol. Menthol was conjugated at the 3-hydroxy

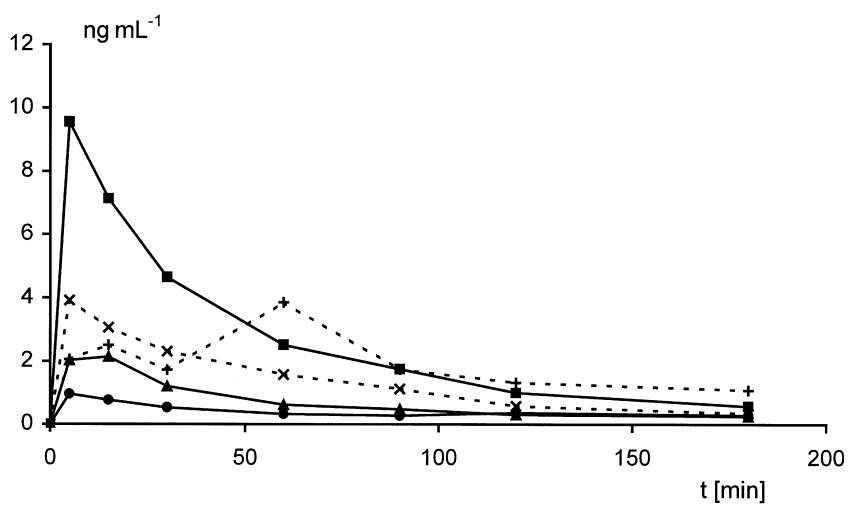

Fig. 1 Plasma levels of $-\boldsymbol{-}-\alpha$-pinene, -0- camphor, $-\boldsymbol{\Delta}-\beta$ pinene, $-x-3$-carene and -+- limonene after dermal application of $2 \mathrm{~g}$ Pinimenthol-S-ointment ${ }^{\circledR}$ at $400 \mathrm{~cm}^{2}$ area in 12 human subjects (19). 


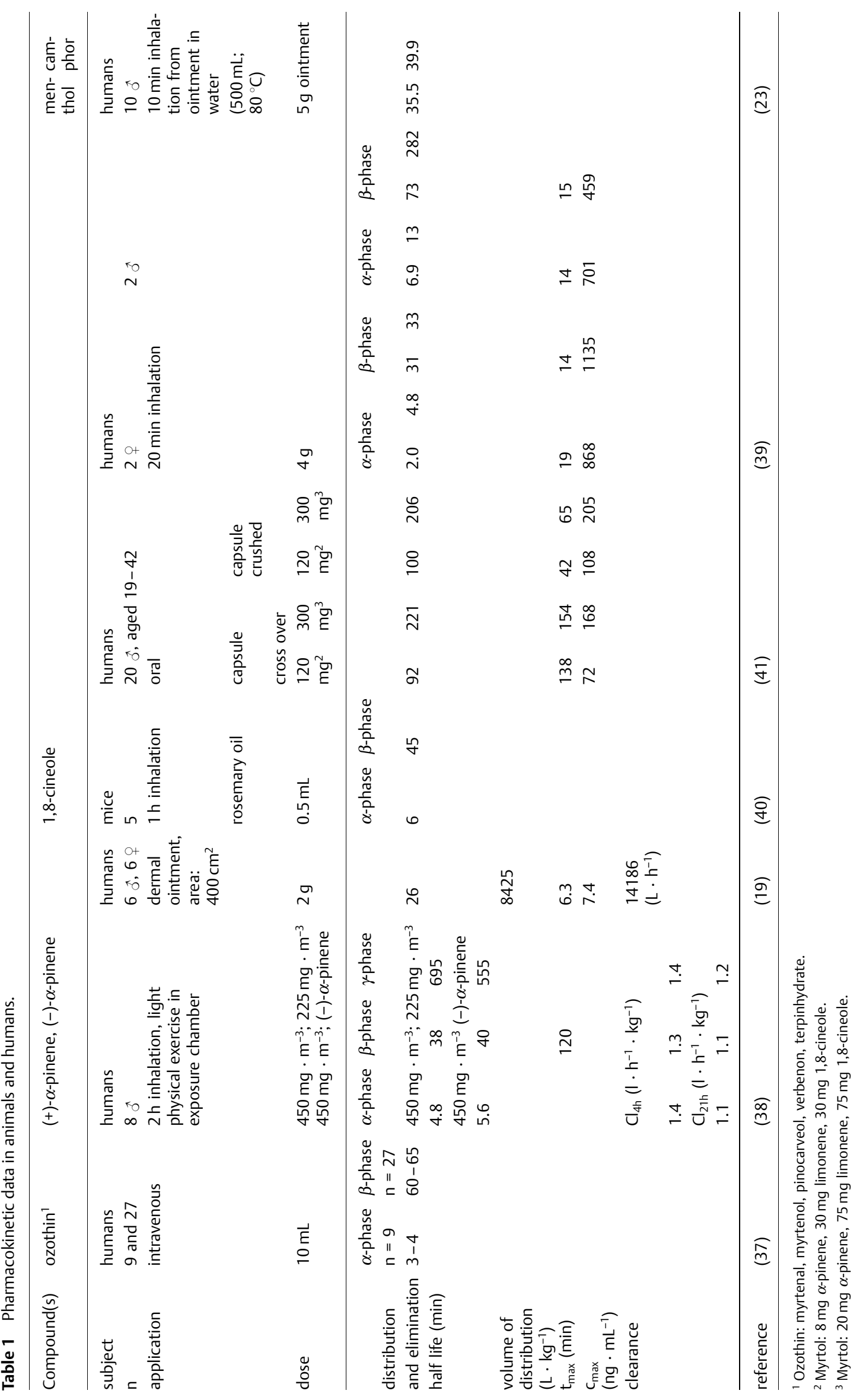




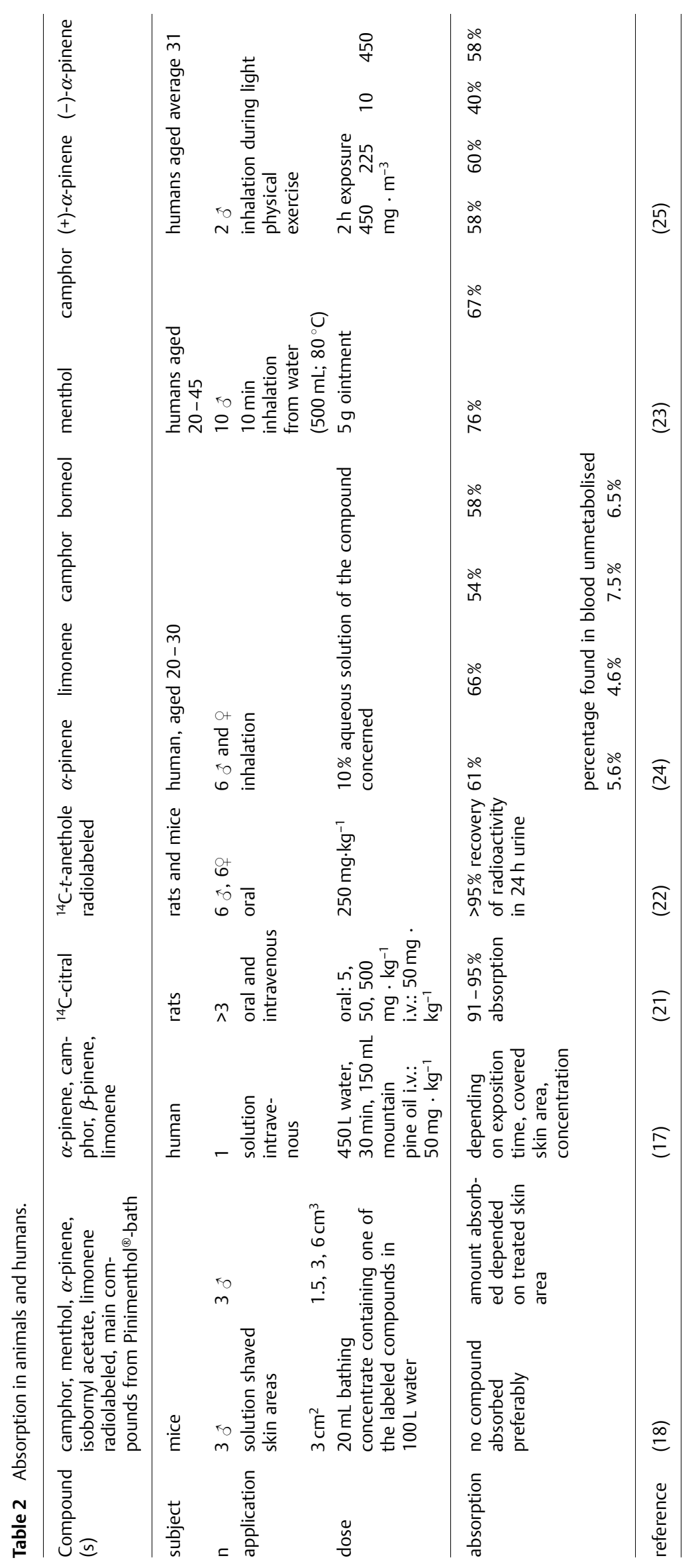




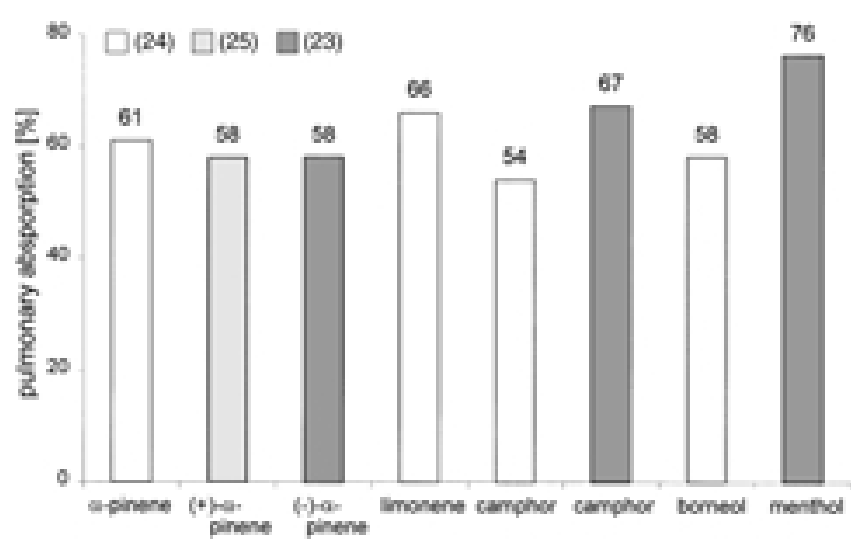

Fig. 2 Pulmonary absorption after inhalation

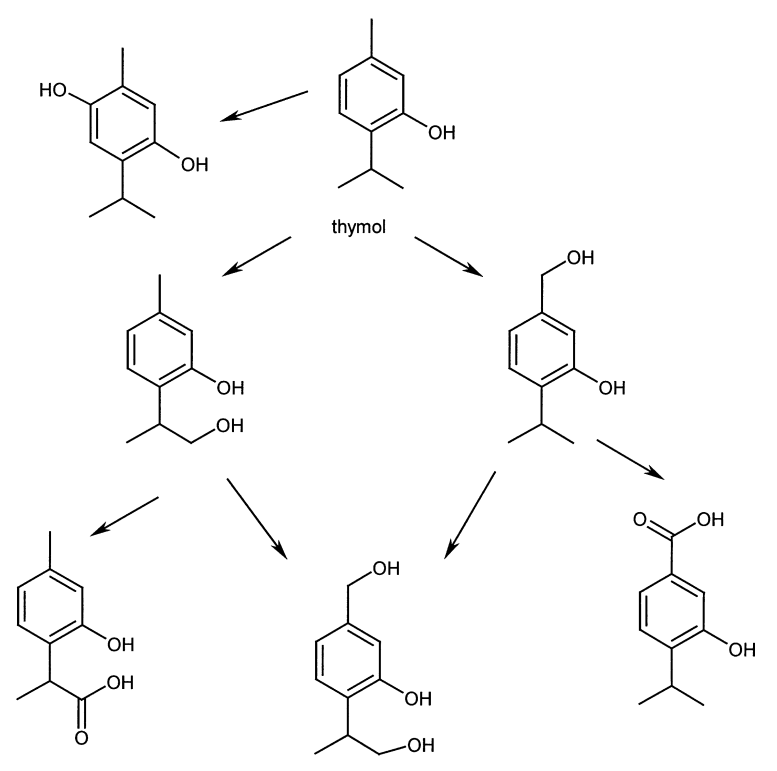

Fig. 3 Urinary phase-I metabolites and suggested metabolic routes of thymol in rats (26).

group (35). Its glucuronide was also the main urinary metabolite in rats $(60 \%)$ (36). Therefore menthol glucuronide seemed to be the main urinary metabolite in both humans and rats.

Investigations of citral (isomeric mixture of neral and geranial) revealed complete and stereoselective metabolism in rats (21). In addition to the liver, other organs were involved in the metabolism. Comparing the routes of excretion after oral, intravenous, and dermal application, a cutaneous first pass effect was suggested (20). (For details see Table 3.)

\section{Pharmacokinetic data}

In general, most essential oils and their components studied so far have been pharmacokinetically characterised by an elimination profile that is at least biphasic (37), (38), (39), (40). This suggests that these compounds are distributed from the blood into other tissues. Due to high clearance and short elimination half lives, accumulation was improbable.
The best approach to obtain basic pharmacokinetic parameters of a compound (half life, volume of distribution, and clearance) is to follow the change in plasma concentrations over time after intravenous injection. However, there was only one study carried out by Kleinschmidt et al. (1985), measuring plasma levels after intravenous injection of a bronchosecretolytic mixture of terpenes $\left(\right.$ ozothin $^{\circledR}$ ) in humans. Plasma concentrations were calculated as total terpene concentrations. The short half life in the $\alpha$-phase of 3 to $4 \mathrm{~min}$ indicated fast distribution of terpenes into tissues. Elimination half life of the $\beta$-phase was 60-65 min due to metabolism and excretion (37).

Pharmacokinetic parameters of $\alpha$-pinene were also determined after dermal application and inhalation (19), (38). The half life in the $\alpha$-phase was very short, about $5 \mathrm{~min}$, followed by longer half lives in the $\beta$-phase ranging from 26 to $38 \mathrm{~min}$. In the latter study (38) a third $\gamma$-phase was determined with an elimination half life of $695 \mathrm{~min}$. The other study (19) showed a rise of $\alpha$-pinene concentrations in a few subjects six to ten hours after dermal application; however, considerable variations due to the methodological difficulties of measuring low concentrations prevented the authors from including these data into a pharmacokinetic calculation. This highlights the importance of long sampling periods combined with sensitive methods for the determination of pharmacokinetic data. The high volume of distribution of $\alpha$-pinene suggested a disposition in compartments, which was likely due to the high affinity to lipophilic structures. Despite a high volume of distribution, the high clearance indicated fast elimination of $\alpha$-pinene. Thus, there should be no accumulation even during long-term administration. In this study high standard deviation values were conspicuous. This might be explained by the heterogenous sample, including both men and women.

After inhalation of 1,8-cineole a substantial difference of elimination half lives in male and female subjects was found (39). Whereas pulmonary absorption and $t_{\max }$ were within a similar range, elimination half lives were at least twice as long in female subjects. Therefore it was assumed that subcutaneous fat was an important factor influencing the elimination of 1,8cineole.

The bioavailability of 1,8-cineole and the pharmacokinetics of myrtol (a mixture of $30 \mathrm{mg}$ 1,8-cineole, $30 \mathrm{mg}$ limonene and $8 \mathrm{mg} \alpha$-pinene), were evaluated after oral administration of crushed and uncrushed capsules (41). Comparison of the cineole plasma levels yielded a relative bioavailability of approximately $100 \%$ for the uncrushed capsules. As expected, plasma levels remained elevated for a longer time after administration of uncrushed capsules. Limonene and $\alpha$-pinene could be detected in only a few subjects.

Elimination data for menthol and camphor after inhalation were fitted to a two-compartment model (23). Elimination half lives were 35.5 and 39.9 min for menthol or camphor, respectively, indicating that there should be no accumulation even during long-term application. (For details see Table 4 ).

\section{Excretion}

Elimination of essential oil compounds was monitored in urine, faeces or expired air. The major part of the compounds 


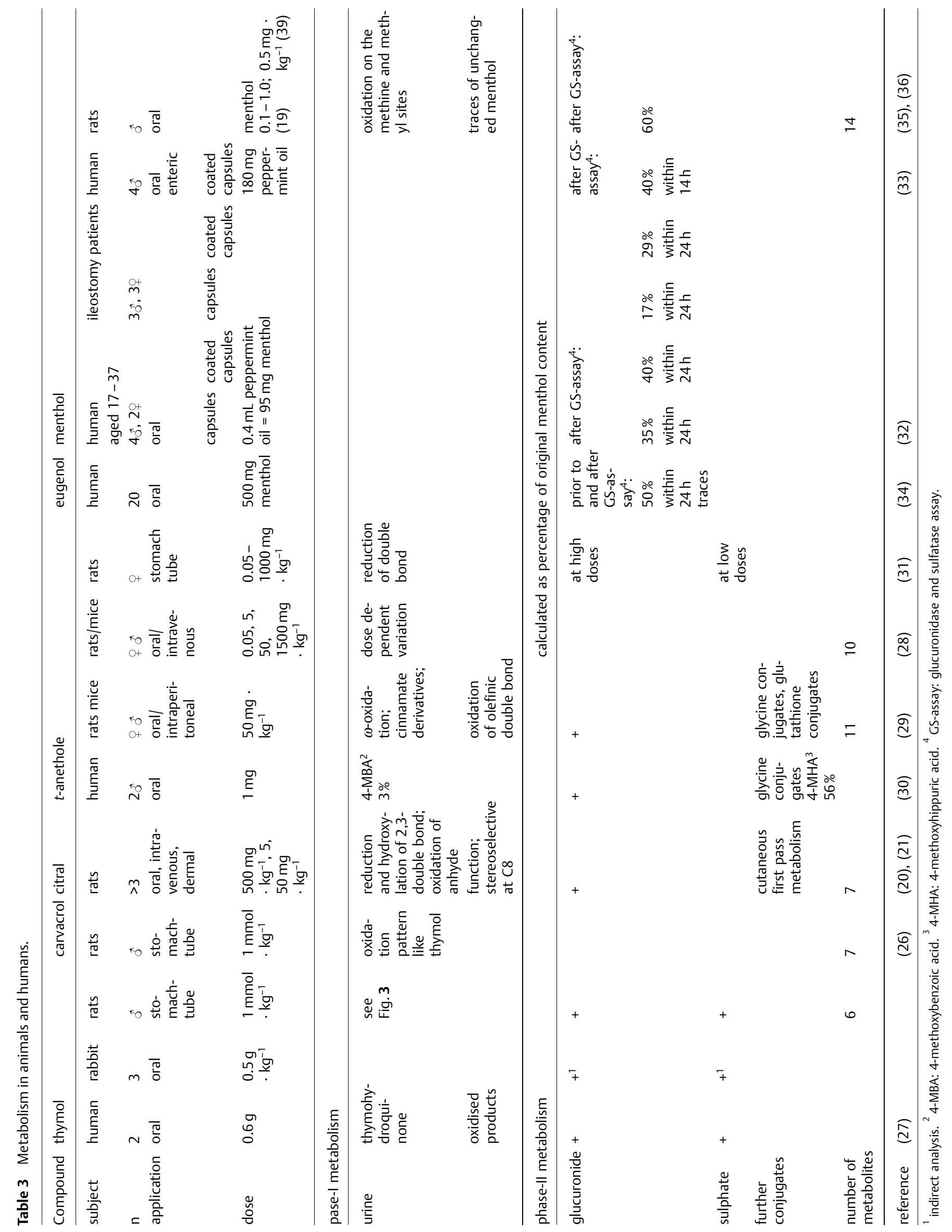


Table 4 Elimination in rodents.

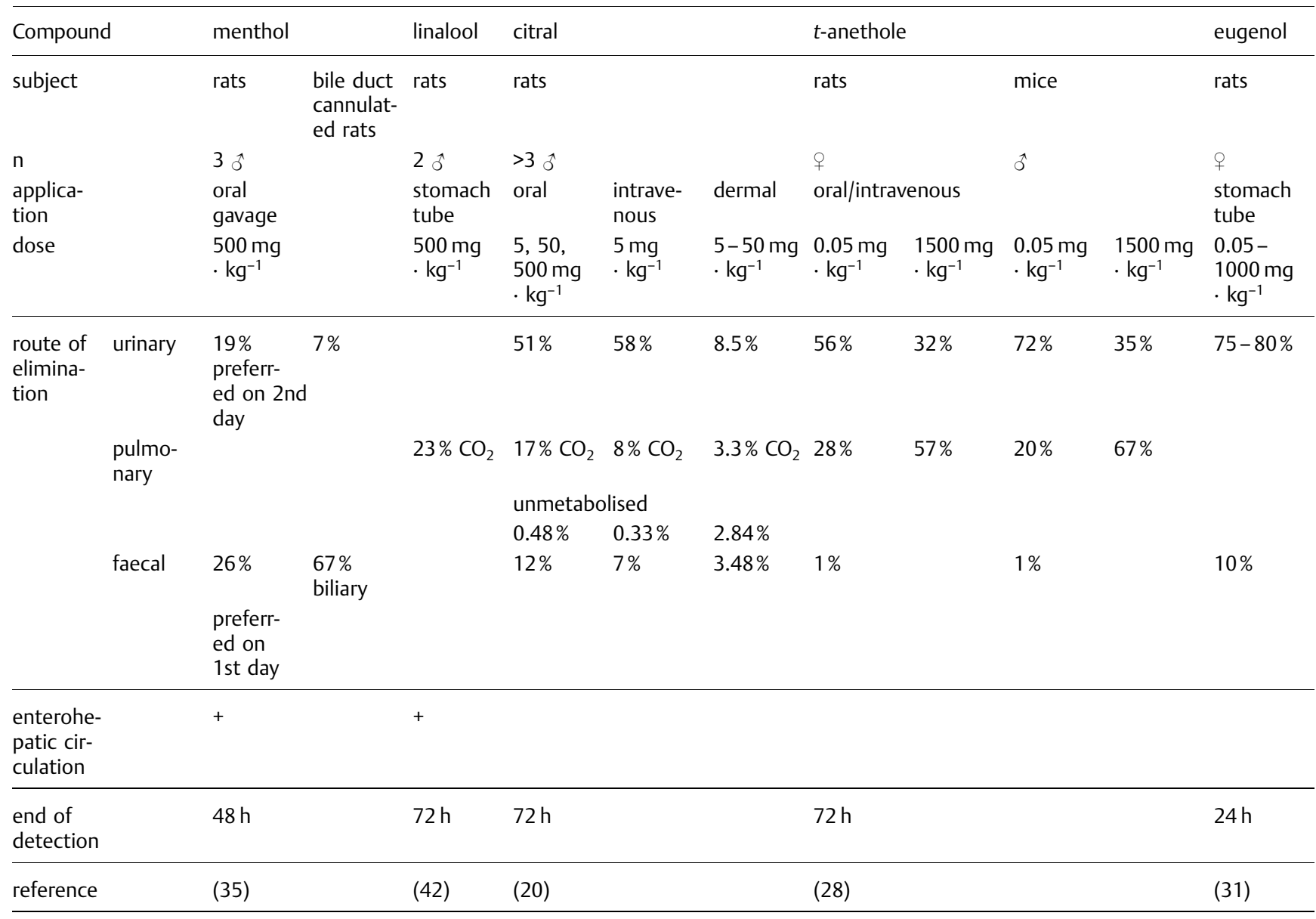

and their metabolites was eliminated by the kidneys and the lung. A minor part was eliminated via the faeces. Only traces of the compounds were eliminated unmetabolised in urine or faeces. Enterohepatic circulation was evident for menthol and linalool delaying their excretion (35), (42).

\section{Pulmonary elimination}

Due to their volatility, essential oil compounds or their metabolites are likely to be exhaled. However, only $1.5-5 \%$ of intravenously injected monoterpenes were eliminated unchanged by the lung. $75-95 \%$ of this fraction were exhaled within the first $10-40 \mathrm{~min}$ (17), (37). The amount of terpenes exhaled decreased with increasing boiling point of the respective compounds (17). The major part of the compounds was assumed to be metabolised and exhaled as $\mathrm{CO}_{2}$ or renally eliminated as terpene conjugates (17), (25), (37). (For details see Table $\mathbf{5}$.)

\section{Balance of elimination}

Complete elimination and excretion of the applied dose was only tracked for citral and $t$-anethole (20), (28). For these compounds urinary excretion was found to be the main route of elimination accounting for over $50 \%$ of the dose (20), (28), followed by pulmonary elimination. Faecal excretion was assumed to be a minor route of elimination.

After oral administration of $t$-anethole in humans, metabolites were mainly excreted renally (approximately 60\%) (30), (43). A smaller fraction was metabolised and eliminated via the lung as ${ }^{14} \mathrm{CO}_{2}$. Cumulative excretion curves indicated that elimination was completed within 24 hours. Increasing doses had no influence on the excretion pattern of $t$-anethole (Fig. 4) (43).

In contrast to these observations, elimination patterns of $t$ anethole in rats and $\alpha$-pinene in humans were dose dependent (28), (25). At low doses, most of the applied ${ }^{14} \mathrm{C}$-labeled $t$ anethole was eliminated through the lung as ${ }^{14} \mathrm{CO}_{2}$, indicating that oxidative $O$-demethylation predominated in rats after application of low doses (Fig. 5). In contrast to $t$-anethole, the percentage of $\alpha$-pinene excreted renally (main metabolites: verbenol) increased with decreasing exposure levels (25). These findings might be the result of saturation of particular metabolic enzymes after administration of high doses.

Changes in excretion profiles according to the kind of application were observed for citral. The differences after oral and intravenous application were interpreted as a consequence of 


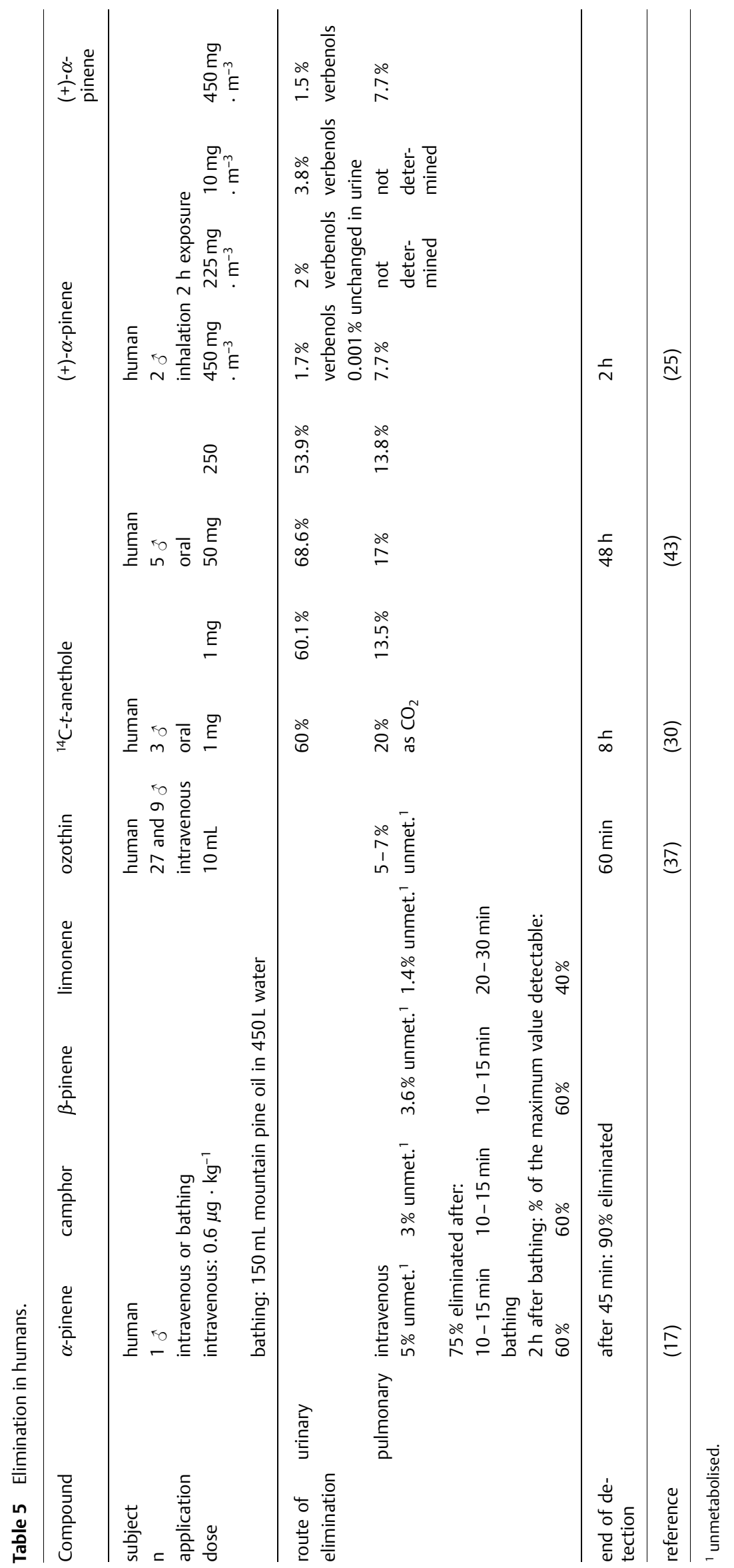


decomposition by intestinal bacteria or first pass metabolism following gastrointestinal absorption. Overall transport or metabolism of citral revealed not to be dose dependent in the dose range studied (20). (For details see Table $\mathbf{4}$ and $\mathbf{5}$ ).

\section{Analytical Methodology of Essential Oil Compounds in Biological Matrices}

In most studies presented here, the lack of documentation of the assay methodology applied is a striking and crucial fact. Appropriate sensitive and selective detection methods are a major prerequisite for the analysis of volatile compounds and their metabolites in biological matrices. Accuracy, precision and specificity have to be evaluated by appropriate validation assays.

Due to their volatile character essential oil compounds are accessible to gas chromatographic analysis (GC). Combined with appropriate detection GC provides a sensitive analytical method with limits of detection in the lower $\mathrm{ng} / \mathrm{mL}$ range. The most selective detection system available today is GC/MS or GC/MS/MS using selected ion monitoring or selected reaction monitoring experiments. However, it has not yet been used for quantitative analysis in pharmacokinetic studies of essential oil components. For quantification in biological matrices at trace levels by GC/MS or GC/MS/MS, standards labeled with stable isotopes are needed.

Urinary metabolites have often been detected by GC analysis after enzymatic hydrolysis of phase II metabolites such as glucuronides and/or sulfates. In most studies the initially nonconjugated free compounds were not determined. This might be the reason for varying results in different studies with similar designs. For sample preparation compounds and the corresponding phase-I metabolites were either extracted from urine or plasma with lipophilic solvents (ethyl acetate, ether), separated by solid-phase extraction or analysed directly via headspace analysis. Lower limits of detection might have been achieved by using other extracting solvents (pentane, hexane, isopropanol) or adsorbents (e.g., ethyl-vinyl-benzene polymer). However, comparative evaluation of the different methods used can hardly be performed since method validation was rarely reported.

Adsorbents were also used to trap and determine pulmonarily eliminated compounds in two studies. A different method was applied by Levin (25). Infrared spectroscopy was used for the determination of pinene concentrations in an exposure chamber and in the exhaled air of the subjects. This method was the only one published which allowed simultaneous and on-line monitoring of exposure concentrations and pulmonary elimination. The limit of detection was not presented.

Determinations of compounds, which become non-volatile by phase-I and phase-II metabolism, require other analytical methods, such as HPLC. In order to achieve sufficient sensitivity, liquid scintillation detection of labeled compounds was used in these studies. However, radioactive labeling is not always the ideal method, because such data do not provide any information on the identity of the analyte. Additionally, exhaled ${ }^{14} \mathrm{CO}_{2}$ was trapped in alkaline solutions or charcoal, a method that carries the risk of underestimation.

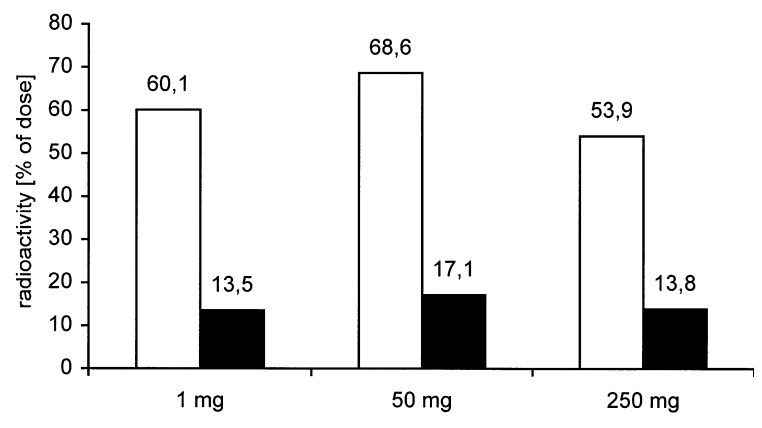

Fig. 4 Urinary $(\square)$ and pulmonary $\left({ }^{14} \mathrm{CO}_{2}\right)(\square)$ elimination after application of different doses of ${ }^{14} \mathrm{C}$-t-anethole to humans (30).

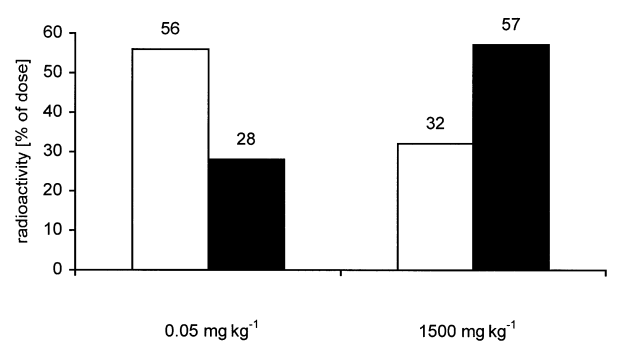

Fig. 5 Urinary $(\square)$ and pulmonary $\left({ }^{14} \mathrm{CO}_{2}\right)(\boldsymbol{\square})$ elimination after application of different doses of ${ }^{14} \mathrm{C}$ - $t$-anethole to rats (28).

Nowadays multi-channel electrochemical detection offers a new, very sensitive detection method with liquid chromatographic analysis which may become significant with regard to non-volatile metabolites in the future.

The published data can only be evaluated with regard to the applied analytical methodology, but satisfactory analytical parameters of the assays used were only reported in a few studies, for example by Kaffenberger et al. and Zimmermann et al. (33), (41). In most other reports the different results obtained in similar studies therefore cannot be put down to differences in analytical methods, although this might have had a major impact on the outcome of the investigations. For all methods used, it is a minimum requirement in method validation to assess and document the precision of retention times, linearity over the desired concentration range, limit of quantification, and analyte recovery at different concentrations.

\section{Conclusions}

Despite the number of studies which provide a large quantity of data for several volatile compounds, there is a lack of good quality pharmacokinetic data in humans.

The few existing pharmacokinetic studies of essential oils after intravenous administration suggest that essential oil components are quickly eliminated in humans with an elimination half life of about one hour. The volume of distribution is considered to be high. Regarding these findings together with the high clearance of essential oil compounds, accumulation is unlikely. 
Most studies suggest that essential oil compounds are quickly absorbed after oral, pulmonary, or dermal administration. Only a small fraction is eliminated unchanged by the lungs, whereas the major portion is metabolised and either eliminated by the kidneys in the form of phase-II conjugates - mainly glucuronides, or exhaled as $\mathrm{CO}_{2}$.

Studies on the pharmacokinetics and bioavailability of essential oils and their compounds require a highly sensitive and specific assay methodology. Differing or even contradictory results from various studies might be caused by differences in the applied analytical methods. This, however, could not be critically evaluated since analytical details were not published in most of the studies. As the assays used might not match the requirements for analytical validation, the results of the studies reviewed have to be considered cautiously.

The data available so far express a great demand for further pharmacokinetic studies in humans. Reliable pharmacokinetic data in humans would be an important key to the question whether a volatile compound or its metabolites may have a potential effect on certain diseases which is therapeutically relevant. Detailed information about absorption, metabolism, distribution and elimination may also be important in the context of safety evaluations of herbal medicinal products. Some basic and principle pharmacokinetic parameters of isolated compounds are reported but they are not linked or compared to respective data in complex mixed essential oils.

\section{References}

${ }^{1}$ Teuscher E. Biogene Arzneimittel. $5^{\text {th }}$ ed. Stuttgart: Wissenschaftliche Verlagsgesellschaft mbH, 1997

2 Malo JL, Boulet LP, Dewitte JD, Cartier A, L'Archeveque J, Cote J, Bedard G, Boucher F, Champagne F, Tessier G. Quality of life of subjects with occupational asthma. Journal of Allergy and Clinical Immunology 1993; 91: 1121 - 7

${ }^{3}$ Grimm G. Antiobstruktive Wirksamkeit von Cineol bei Atemwegserkrankungen. Therapiewoche 1987; 37: 4306-11

${ }^{4}$ Dorow P. Welchen Einfluß hat Cineol auf die mukoziliäre Clearance? Chronisch-obstruktive Bronchitis. Therapiewoche 1989; 39: $2652-4$

${ }^{5}$ Federspil P, Wulkow R, Zimmermann T. Wirkung von Myrtol standardisiert bei der Therapie der akuten Sinusitis - Ergebnisse einer doppelblinden, randomisierten Multicenterstudie gegen Placebo. Laryngo-Rhino-Otologie 1997; 76: 23 - 7

${ }^{6}$ Ernst E, März RW, Sieder C. A controlled multi-centre study of herbal versus secretolytic drugs for acute bronchitis. Phytomedicine 1997; 4: 287-93

${ }^{7}$ Morgenstern E. Die antiphlogistische Wirkung von Bronchipret und seiner Komponenten im Rattenpfoten-Ödem-Modell. In: März R, Editor. Bronchitis. Neue Erkenntnisse zu Wirkungen und Wirksamkeit von Arzneipflanzen. Basel, Freiburg, Paris: Karger, 1998: 1 - 8

${ }^{8}$ Liu JH, Chen GH, Yeh HZ, Huang CK, Poon SK. Enteric-coated peppermint-oil capsules in the treatment of irritable bowel syndrome: a prospective, randomized trial. Journal of Gastroenterology $1997 ; 32: 765-8$

${ }^{9}$ Pittler MH, Ernst E. Peppermint oil for irritable bowel syndrome: a critical review and metaanalysis. American Journal of Gastroenterology 1998; 93: 1131-5

${ }^{10}$ May B, Kuntz HD, Kieser M, Kohler S. Efficacy of a fixed peppermint oil/caraway oil combination in non-ulcer dyspepsia. Arzneimittelforschung 1996; 46: 1149-53
11 Göbel H, Fresenius J, Heinze A, Dworschak M, Soyka D. Effektivität von Oleum menthae piperitae und von Paracetamol in der Therapie des Kopfschmerzes vom Spannungstyp. Nervenarzt 1996; 67: $672-81$

${ }^{12}$ Loew D. Ätherische Öle in der Behandlung der Erkältungskrankheiten. In: Tyrrell DAJ, Editor. Erkältungskrankheiten. Ein Lehrbuch für die Praxis. Stuttgart, Jena, New York: Fischer, 1996: 1008

${ }^{13}$ Göckeritz D, Weuffen W, Höppe H. Terpene und Terpenderivate vom Carvon- und Camphertyp - ihre antimikrobiellen und verminoxen Eigenschaften. Pharmazie 1974; 29: 339-43

${ }^{14}$ Maruzella JC, Liguori L. The in vitro antifungal activity of essential oils. Journal of the American Pharmaceutical Association 1958; 47: $250-4$

${ }^{15}$ Janssen AM, Chin NLJ, Schefer JJC, Baerheim Svendsen A. Screening for antimicrobial activity of some essential oils by the agar overlay technique. Pharmaceutisch Weekblad 1986; 8: 289-92

${ }^{16}$ Pattnaik S, Subramanyam VR, Kole C. Antibacterial and antifungal activity of ten essential oils in vitro. Microbios 1996; 86: 237-46

${ }^{17}$ Römmelt H, Zuber A, Dirnagl K, Drexel H. Zur Resorption von Terpenen aus Badezusätzen. Münchner Medizinische Wochenschrift 1974; 116: 537 - 40

${ }^{18}$ Schäfer R, Schäfer W. Die perkutane Resorption verschiedener Terpene - Menthol, Campher, Limonen, Isobornylacetat, alpha-Pinen - aus Badezusätzen. Arzneimittelforschung 1982; 32: 56-8

${ }^{19}$ Schuster O, Haag F, Priester H. Transdermale Absorption von Terpenen aus den etherischen Ölen der Pinimenthol-S-Salbe. Die Medizinische Welt 1986; 37: 100-2

${ }^{20}$ Diliberto JJ, Usha G, Birnbaum LS. Disposition of citral in male Fischer rats. Drug Metabolism and Disposition 1988; 16: 721 - 7

${ }^{21}$ Diliberto JJ, Srinivas P, Overstreet D, Usha G, Burka LT, Birnbaum LS. Metabolism of citral, an alpha,beta-unsaturated aldehyde, in male F344 rats. Drug Metabolism and Disposition 1990; 18: 866 75

${ }^{22}$ Bounds SV, Caldwell J. Pathways of metabolism of $\left[1^{\prime}-14 \mathrm{C}\right]$-transanethole in the rat and mouse. Drug Metabolism and Disposition 1996; 24: 717-24

${ }^{23}$ Römmelt H, Schnitzer W, Swoboda M, Senn E. Pharmakokinetik ätherischer Öle nach Inhalation mit einer terpenhaltigen Salbe. Zeitschrift für Phytotherapie 1988; 9: 14-6

${ }^{24}$ Römmelt H, Drexel H, Dirnagl K. Wirkstoffaufnahme aus pflanzlichen Badezusätzen. Die Heilkunst 1978; 91: 249-54

${ }^{25}$ Levin JO, Eriksson K, Falk A, Lof A. Renal elimination of verbenols in man following experimental alpha-pinene inhalation exposure. International Journal of Occupational and Environmental Health 1992; 63: $571-3$

${ }^{26}$ Austgulen L, Solheim E, Scheline R. Metabolism in rats of p-cymene derivatives: carvacrol and thymol. Pharmacology and Toxicology 1987; 61: $98-102$

27 Takada M, Agata I, Sakamoto M, Yagi N, Hayashi N. On the metabolic detoxification of thymol in rabbit and man. Journal of Toxicological Sciences 1979; 4: 341 -50

${ }^{28}$ Sangster SA, Caldwell J, Smith RL. Metabolism of anethole. II. Influence of dose size on the route of metabolism of trans-anethole in the rat and mouse. Food and Chemical Toxicology 1984; 22: $707-13$

29 Sangster SA, Caldwell J, Smith RL, Farmer PB. Metabolism of anethole. I. Pathways of metabolism in the rat and mouse. Food and Chemical Toxicology 1984; 22: 695-706

${ }^{30}$ Sangster SA, Caldwell J, Hutt AJ, Anthony A, Smith RL. The metabolic disposition of [methoxy- ${ }^{-14} \mathrm{C}$ ]-labelled trans-anethole, estragole and $p$-propylanisole in human volunteers. Xenobiotica 1987; 17: $1223-32$

${ }^{31}$ Sutton D, Sangster S, Caldwell J. Dose-dependent variation in the disposition of eugenol in the rat. Biochemical Pharmacology 1985; $34: 465-6$ 
${ }^{32}$ Somerville KW, Richmond CR, Bell GD. Delayed release peppermint oil capsules (Colpermin) for the spastic colon syndrome: a pharmacokinetic study. British Journal of Clinical Pharmacology 1984; 18: 638-40

${ }^{33}$ Kaffenberger RM, Doyle MJ. Determination of menthol and menthol glucuronide in human urine by gas chromatography using an enzyme-sensitive internal standard and flame ionization detection. Journal of Chromatography 1990; 527: 59-66

${ }^{34}$ Bell G, Henry D, Richmond C. A specific g.l.c. assay for menthol in urine. British Journal of Clinical Pharmacology 1981; 12: 281

${ }^{35}$ Yamaguchi T, Caldwell J, Farmer PB. Metabolic fate of [ $\left.{ }^{3} \mathrm{H}\right]-\mathrm{L}-\mathrm{men}-$ thol in the rat. Drug Metabolism and Disposition 1994; 22: 61624

${ }^{36}$ Mans M, Pentz R. Pharmacokinetics of menthol in the rat. NauynSchmiedebergs Archives of Pharmacology 1987; 335: R6

${ }^{37}$ Kleinschmidt J, Römmelt H, Zuber A. The pharmacokinetics of the bronchosecretolytic ozothin after intravenous injection. International Journal of Clinical Pharmacology, Therapy, and Toxicology 1985; $23: 200-3$

${ }^{38}$ Falk A, Hagberg M. Uptake, distribution and elimination of alphapinene in man after exposure by inhalation. Scandinavian Journal of Work, Environment and Health 1990; 16: $372-8$

39 Jager W, Nasel B, Nasel C, Binder R, Stimpfl T, Vycudilik W, Buchbauer G. Pharmacokinetic studies of the fragrance compound 1,8cineol in humans during inhalation. Chemical Senses 1996; 21: $477-80$

${ }^{40}$ Kovar K, Gropper B, Friess D, Ammon H. Blood levels of 1,8-cineole and locomotor activity of mice after inhalation and oral administration of rosemary oil. Planta Medica 1987; 53: 315-8

${ }^{41}$ Zimmermann T, Seiberling M, Thomann P, Karabelnik D. Untersuchungen zur relativen Bioverfügbarkeit und zur Pharmakokinetik von Myrtol standardisiert. Arzneim.-Forsch./Drug Res. 1995; 45: $1198-201$

${ }^{42}$ Parke D, Rahman Q, Walker R. The absorption, distribution and excretion of linalool in the rat. Biochemical Society Transactions 1974; $2: 612-8$

${ }^{43}$ Caldwell J, Sutton JD. Influence of dose size on the disposition of trans-[methoxy $\left.-{ }^{14} \mathrm{C}\right]$-anethole in human volunteers. Food and Chemical Toxicology 1988; 26: 87-91

\section{PD. Dr. Markus Veit}

Zentralinstitut Arzneimittelforschung GmbH

Kranzweiherweg 10

53489 Sinzig

Germany

E-mail: markus.veit@za-sinzig.de

Fax: +49 (0) 2642983740 